\title{
MAPEAMENTO DE ACESSIBILIDADE DA UFES: UMA ANÁLISE DOS CAMINHOS DA UNIVERSIDADE FEDERAL DO ESPÍRITO SANTO
}

\author{
Kaísa Souza \\ Universidade Federal do Espírito Santo \\ kaisa.souza@gmail.com \\ Luíza Mariani \\ Universidade Federal do Espírito Santo \\ mariani.luiza@gmail.com \\ Mauro Pinheiro, Dr. \\ Universidade Federal do Espírito Santo \\ Escola Superior de Desenho Industrial - UERJ \\ mauro.pinheiro@ufes.br \\ mpinheiro@esdi.uerj.br
}

Resumo: $\mathrm{O}$ artigo trata do mapeamento de acessibilidade dos caminhos do campus Goiabeiras da Universidade Federal do Espírito Santo, para cadeirantes e para pessoas que apresentam alguma dificuldade de locomoção. Descreve-se a metodologia utilizada na análise dos caminhos, numa perspectiva de Design Centrado no Usuário, destacando-se a utilização da cadeira de rodas, que possibilitou identificar diferentes graus de dificuldade dos trajetos. Descreve-se ainda o sistema de representação desenvolvido para apresentar os resultados do diagnóstico, através de um mapa no qual pictogramas indicavam a natureza dos problemas encontrados, e os diferentes níveis de severidade percebidos nos trajetos eram indicados por padrões cromáticos.

Palavras-chave: acessibilidade; mapas; sinalização

\begin{abstract}
The article describes the accessibility mapping of the Federal University of Espirito Santo's campus, considering the needs of wheelchair users and people with limited mobility. It describes the methodology used in the analysis of the campus paths, highlighting the use of a wheelchair, which enabled to identify the different effort levels to go through these paths. It also describes the representation system developed to present the diagnosis' results, in which a map with pictograms represents the different types of problems, and color code indicates the severity levels perceived.
\end{abstract}

Keywords: accessibility; maps; signage system 


\section{INTRODUÇÃO}

O tema da acessibilidade tem ganhado importância no Brasil ao longo dos anos. De acordo com o Censo 2010, quase um quarto da população brasileira $(23,92 \%)$ possui algum tipo de deficiência (OLIVEIRA, 2012), sendo portanto fundamental garantir a participação plena, em igualdade de condições, desse extrato populacional nas diversas atividades do cotidiano.

A legislação brasileira segue a definição da ABNT NBR 9050:2015, que descreve acessibilidade como sendo a "possibilidade e condição de alcance para utilização, com segurança e autonomia, de espaços, mobiliários, equipamentos urbanos, edificações, transportes, informação e comunicação, inclusive seus sistemas e tecnologias, bem como de outros serviços e instalações abertos ao público, de uso público ou privados de uso coletivo, tanto na zona urbana como na rural, por pessoa com deficiência ou com mobilidade reduzida" (BRASIL, 2015; ABNT, 2015).

Desde 2000 o governo reconhece a necessidade de parâmetros que garantam a acessibilidade, estabelecendo diretrizes gerais para o projeto de ambientes construídos, meios de transporte e sistemas digitais através da Lei 10.098/2000, conhecida como "Lei de acessibilidade". No entanto, somente a partir de 2008, ao ratificar texto da Convenção das Nações Unidas sobre os Direitos das Pessoas com Deficiência, o Brasil de fato trabalha para ampliar a acessibilidade no país, comprometendo-se a apresentar resultados ao Secretario da ONU e demais Estados Partes, em intervalos mínimos de quatro anos (BRASIL, 2008, Art. 35ㅇ).

Em 2015 entrou em vigência a Lei 13.146/2015, Lei Brasileira de Inclusão da Pessoa com Deficiência (Estatuto da Pessoa com Deficiência), "destinada a assegurar e a promover, em condições de igualdade, o exercício dos direitos e das liberdades fundamentais por pessoa com deficiência, visando à sua inclusão social e cidadania" (BRASIL, 2015), ampliando a discussão para além da acessibilidade do espaço construído, transportes e meios digitais, para discutir direitos a uma participação plena em diferentes esferas da vida cotidiana.

A acessibilidade está intimamente relacionada ao Design. Bonsiepe (1996) entende o Design como o campo de conhecimento que trata do projeto de interfaces. Para o autor, a interface não deve ser entendida como "uma coisa", mas como "o espaço no qual se estrutura a interação entre corpo, ferramenta (objeto ou signo) e objetivo da ação" (idem, p.12). Assim, os designers projetam interfaces que permitem que indivíduos desempenhem ações no mundo - seja uma ação instrumental ou uma ação comunicativa.

No que se refere ao projeto dessas interfaces, podemos resumir as estratégias para garantir acessibilidade em duas vertentes: a do Design Universal, e a do projeto de adaptações e tecnologias assistivas.

O Design Universal é definido como "a concepção de produtos, ambientes, programas e serviços a serem usados por todas as pessoas, sem necessidade de adaptação ou de projeto específico, incluindo os recursos de tecnologia assistiva" (BRASIL, 2015, Art. 3o, Inciso II; ABNT NBR 9050:2015, p.4). Trata, portanto, do projeto de sistemas que possam ser utilizados por qualquer pessoa, tenha ela deficiência física ou não. É uma abordagem que deve orientar o projeto desde seu início.

Nos projetos em que o conceito de Design Universal não foi seguido desde o início, parte-se para adaptações que permitam a utilização dos sistemas por pessoas com deficiências físicas, alinhando-se com o princípio de tecnologia assistiva. O Art. 3으, 
Inciso III, da Lei 13.146/2015 define tecnologia assistiva ou ajuda técnica como "produtos, equipamentos, dispositivos, recursos, metodologias, estratégias, práticas e serviços que objetivem promover a funcionalidade, relacionada à atividade e à participação da pessoa com deficiência ou com mobilidade reduzida, visando à sua autonomia, independência, qualidade de vida e inclusão social".

No âmbito das universidades públicas, as ações para garantir a acessibilidade se dão em ambas as frentes. Muitos campi e suas edificações não foram projetados tendo uma preocupação com o acesso universal, sendo necessário realizar adaptações $a$ posteriori. Para avançar com a acessibilidade nas universidades públicas federais, 0 Governo Federal, através da Secretaria de Direitos Humanos da Presidência da República, criou o Programa de Acessibilidade na Educação Superior - Incluir. ${ }^{1} \mathrm{O}$ programa dispõe recursos específicos do Ministério da Educação para as universidades desenvolverem ações de acessibilidade, apoiando também a criação e reestruturação de Núcleos de Acessibilidade nas universidades federais.

A Universidade Federal do Espírito Santo enquadra-se no grupo de universidades cujos espaços e edificações não foram planejados levando em consideração o acesso universal. Neste artigo discutimos os métodos e técnicas utilizados para realizar o mapeamento de acessibilidade da Ufes, que compreendeu um diagnóstico da situação de acessibilidade do campus Goiabeiras, bem como o sistema de representação visual desenvolvido para comunicar os diferentes graus de acessibilidade percebidos, de modo a possibilitar o planejamento de ações mitigantes pela Prefeitura Universitária da Ufes. A pesquisa foi realizada pela equipe do ProDesign Ufes, Laboratório de Projetos em Design, que desenvolve projetos de sinalização dos quatro campi da Ufes.

\section{CONTEXTO DO PROJETO}

O mapeamento de acessibilidade do campus Goiabeiras da Universidade Federal do Espírito Santo foi desenvolvido pelo ProDesign Ufes, Laboratório de Projetos em Design do Departamento de Desenho Industrial desta universidade. Contando atualmente com dois coordenadores, professores do Departamento de Desenho Industrial, e quatorze alunos do curso de Design, o ProDesign Ufes surgiu como um programa de extensão universitária, a partir da demanda da administração central da Ufes, no sentido de desenvolver projetos de sinalização para os seus quatro campi: os de Goiabeiras e Maruípe localizados em Vitória, o campus de São Mateus no norte do Espírito Santo e o campus de Alegre, no interior do Estado, mais ao sul.

Desde 2013 o ProDesign Ufes vem desenvolvendo projetos de sinalização, focando principalmente na sinalização dos trajetos de pedestres e veículos dos campi Goiabeiras e São Mateus. Desde o início um dos princípios norteadores do projeto foi garantir que a sinalização fosse acessível a pessoas com deficiências físicas, na perspectiva do Design Universal ${ }^{2}$. Com isso, passou-se a considerar a diversidade

\footnotetext{
${ }^{1}$ Site do Programa de Acessibilidade na Educação Superior - Incluir: http://bit.ly/acessibilidade-naeducacao-superior

${ }^{2}$ Nas etapas iniciais de desenvolvimento do projeto de sinalização, foram feitas entrevistas e testes com pessoas com diferentes tipos de deficiência visual, de modo a orientar definições projetuais que permitissem futuramente a utilização do sistema por essa audiência. Estas questões não serão tratadas neste artigo. Aqui interessa apenas destacar que o contato com o público com deficiências físicas foi fundamental para sensibilizar a equipe às questões de acessibilidade.
} 
humana, de forma a respeitar as diferenças existentes entre as pessoas e a garantir a acessibilidade a todos os componentes do ambiente.

A análise de acessibilidade da Ufes foi iniciada a partir da necessidade de indicar quais dentre os diversos estacionamentos do campus seriam acessíveis a pessoas com deficiência física, especialmente cadeirantes ${ }^{3}$. A intenção era sinalizar os estacionamentos mais adequados - isto é, aqueles dentro dos padrões estabelecidos pelas normas de acessibilidade da ABNT NBR:9050 - aos motoristas cadeirantes ${ }^{4}$.

A partir desse diagnóstico, ficou claro que a experiência dos usuários com deficiência física não se resumia à etapa de identificação dos locais adequados para estacionar o veículo, e que se estendia por todo o trajeto dentro do campus, o que levou a equipe do laboratório à ampliação do foco do trabalho. $O$ intuito da pesquisa então passou a ser realizar o mapeamento do campus de modo a diagnosticar a situação atual de acessibilidade dos caminhos ${ }^{5}$ da Ufes, e com isso ter um retrato fiel da realidade cotidiana de quem apresenta dificuldades de locomoção. Esse mapeamento serviria não só para fundamentar algumas decisões do projeto de sinalização em desenvolvimento, como também articular soluções aos problemas encontrados junto à Prefeitura Universitária - que até então não possuía um levantamento desta natureza.
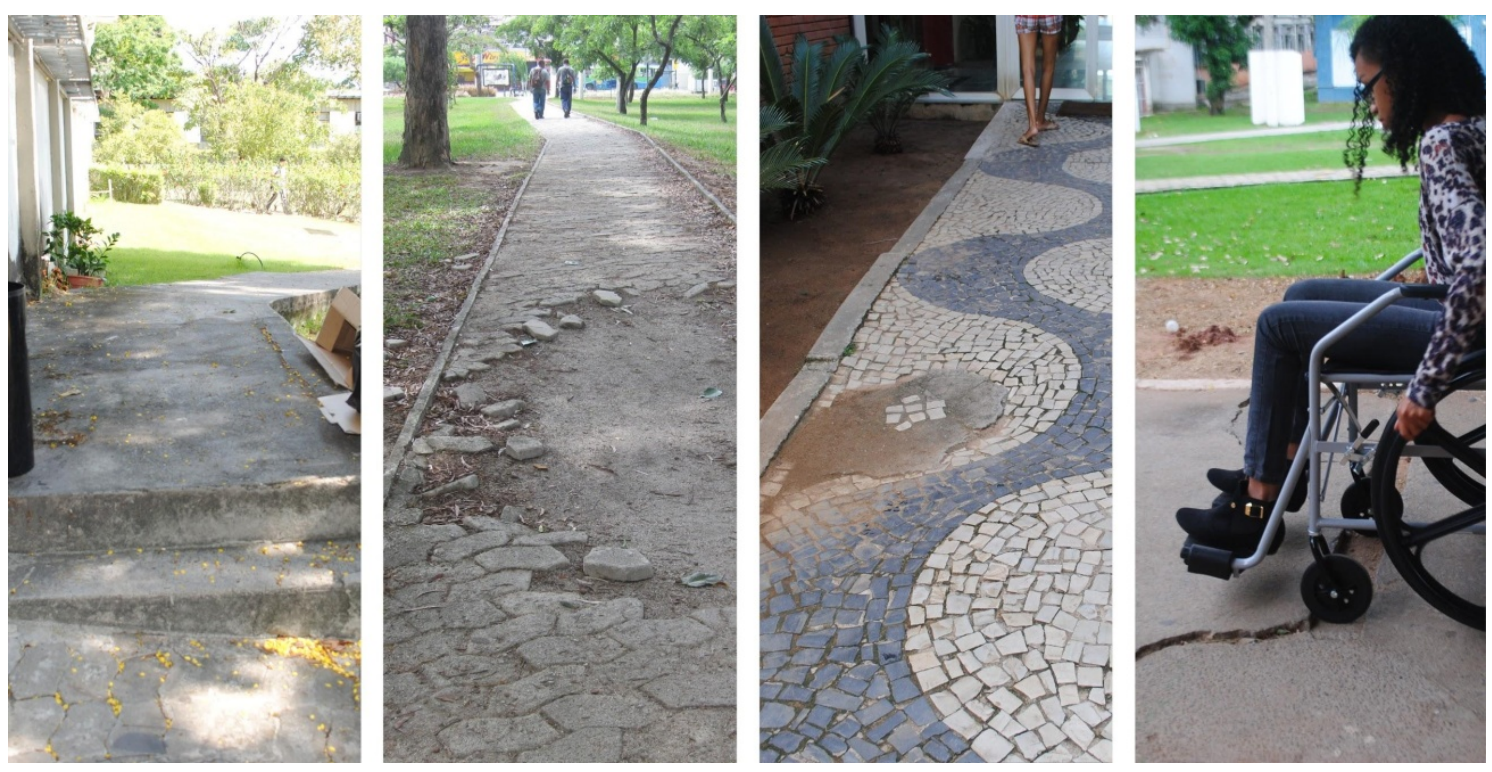

Figura 1: diversas barreiras existentes no campus: degraus, calçamento sem manutenção, buracos e desníveis. Fonte: elaborado pelos autores, com base na pesquisa realizada

\footnotetext{
${ }^{3}$ Entende-se que os cadeirantes apresentam condições de mobilidade reduzidas, e que garantidas as condições de acessibilidade para estes indivíduos, garante-se por extensão o acesso a pessoas com limitações motoras menos severas.

${ }^{4}$ Muitos espaços da Ufes são utilizados irregularmente como estacionamentos, a despeito de não serem adequados para tal uso. Em geral estes espaços são em chão de terra, sem calçamento ou acessos adequados, portanto foram desconsiderados em nossa análise.

${ }^{5}$ Neste artigo tratamos da análise das áreas de circulação do campus, considerando os caminhos externos e principais acessos aos prédios. A análise do interior das edificações ocorrerá futuramente.
} 


\section{MÉTODOS UTILIZADOS}

No início a equipe envolvida com o projeto estudou detidamente a norma ABNT NBR 9050 sobre acessibilidade, de modo a conhecer os parâmetros que deveriam guiar a análise dos caminhos do campus. A experiência preliminar da análise dos estacionamentos ajudou a organizar um sistema de notação que facilitasse o registro das observações in loco, de modo a garantir que todos os critérios fossem observados. Foram analisados 30 estacionamentos, numerados para facilitar o controle, e foram verificados os seguintes pontos: se haviam vagas reservadas à pessoas com deficiência física e idosos; se a porcentagem de vagas para cadeirantes em relação ao total de vagas estava de acordo com o estipulado pela ABNT NBR 9050; se a sinalização destas vagas estava correta; se haviam rampas de acesso quando necessário; se as vagas reservadas encontravam-se próximas às rampas; Além disso, foi feita a verificação do estado das rampas, observando se apresentavam-se em bom estado para o acesso das pessoas com deficiência física.

Os instrumentos utilizados nessa primeira etapa foram o mapa da Ufes e uma planilha, desenvolvida para auxiliar a documentação (Figuras 2 e 3).

\begin{tabular}{|c|c|c|c|c|}
\hline Estacionamento & Vagas cadeirantes & Rampa. Quantas? & OBS. & $N^{\circ}$ vagas \\
\hline 1 & 1 & 1 & & 40 \\
\hline 2 & 0 & 3 & precisa de vaga para cadeirante e idoso & 70 \\
\hline 3 & 3 & 0 & possui 3 vagas para idoso & 133 \\
\hline 4 & 2 & 2 & possui 4 vagas para idoso & 159 \\
\hline 5 & 1 & 1 & sem marcação & 60 \\
\hline 6 & & & & \\
\hline 7 & 1 & & possui 1 vaga para idoso & 324 \\
\hline 8 & 1 & & & 70 \\
\hline 9 & & & & ? \\
\hline 10 & 1 & 4 & possui 1 vaga para idoso & 40 \\
\hline 11 & 0 & & & 30 \\
\hline 12 & & & & 60 \\
\hline 13 & & & & $x$ \\
\hline 14 & & 1 & & 30 \\
\hline 15 & 0 & não tem necessidade & muito longe dos prédios e caminhos & 80 \\
\hline 16 & & & & 60 \\
\hline 17 & sem marcação & & & \\
\hline 18 & & & & \\
\hline 19 & 0 & 1 & & 20 \\
\hline 20 & 1 & 3 & & 98 \\
\hline 21 & & & & \\
\hline 22 & 1 & & & \\
\hline 23 & 0 & & sem marcação & $x$ \\
\hline 24 & 0 & & & 25 \\
\hline 25 & & & estacionamento privado & \\
\hline 26 & & & sem marcação e asfalto & \\
\hline 27 & 0 & sem marcação & aparenta estar em construção & 15 \\
\hline 28 & 2 & 1 & possui gelo baiano em uma das entradas para os prédios & 98 \\
\hline 29 & 0 & 0 & 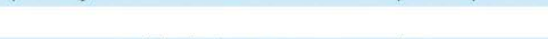 & 68 \\
\hline 30 & 0 & & chão de terra e sem marcação & \\
\hline
\end{tabular}

Figura 2: planilha de síntese da análise dos estacionamentos da Ufes.

Fonte: elaborado pelos autores, com base na pesquisa realizada 


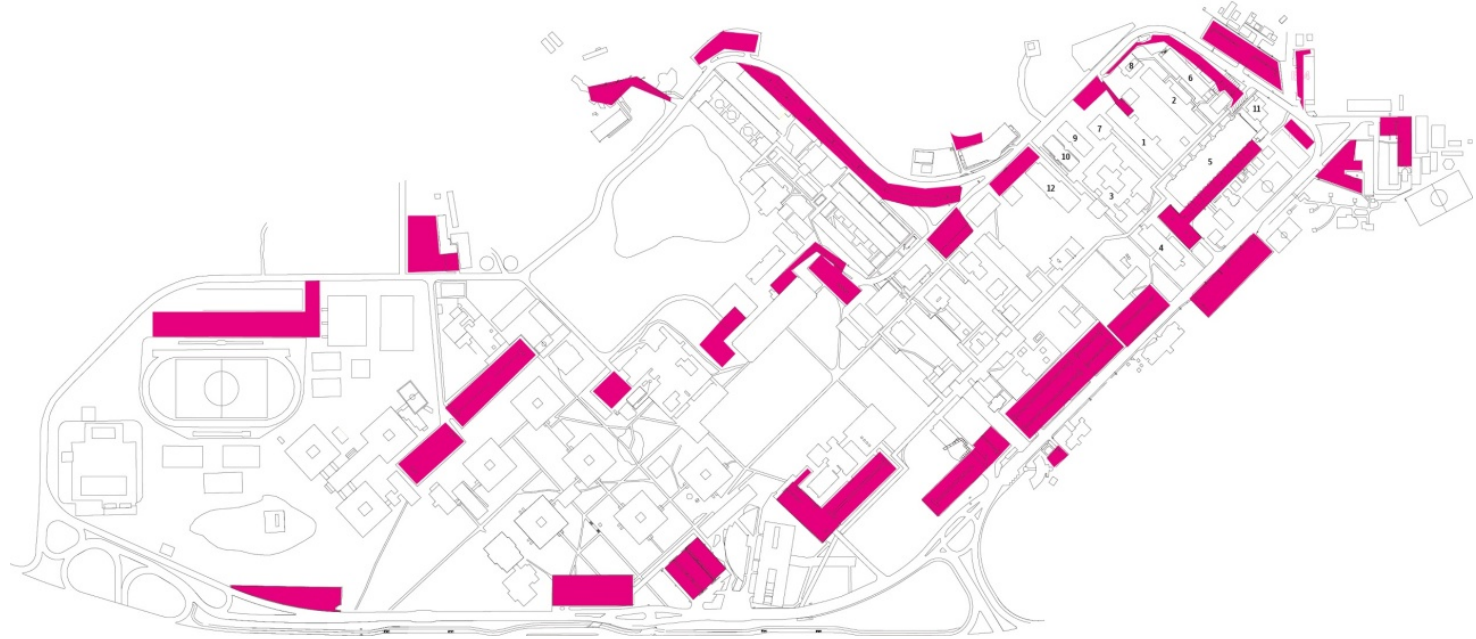

Figura 3: mapa dos estacionamentos da Ufes.

Fonte: elaborado pelos autores, com base na pesquisa realizada

\subsection{Design centrado no usuário: colocando-se no lugar do outro}

Se os critérios objetivos da norma ABNT foram suficientes para a análise dos estacionamentos, ao ampliarmos o foco do projeto para todos os caminhos do campus, tornou-se fundamental analisar os graus de dificuldade de deslocamento nestes caminhos. Esse tipo de análise demandava uma avaliação mais subjetiva do que a mera observação da existência ou não de rampas e vagas, e a notação em uma lista de verificação. Numa perspectiva de Design Centrado no Usuário, sentiu-se necessidade de vivenciar o mais próximo possível a realidade cotidiana dos cadeirantes, de modo a obter uma análise que partisse da sua perspectiva. Entretanto, apesar de contarmos com dados sobre os alunos e funcionários cadeirantes frequentadores do campus, não foi possível contactar essas pessoas dentro do prazo destinado à realização deste estudo. Ademais, seria difícil contar com a participação efetiva desses usuários na análise de todos os caminhos, uma vez que a extensão do campus é grande ${ }^{6} \mathrm{e}$ demandaria um tempo incompatível com a disponibilidade de qualquer colaborador voluntário. A solução encontrada foi adquirir uma cadeira de rodas através de uma das estagiárias do laboratório. A intenção era possibilitar que as pesquisadoras se colocassem no lugar dos cadeirantes, e consequentemente tivessem uma visão mais próxima possível da situação estudada (Figura 4).

\footnotetext{
${ }^{6} \mathrm{O}$ campus Goiabeiras tem cerca de 1,5 milhão de metros quadrados.
} 

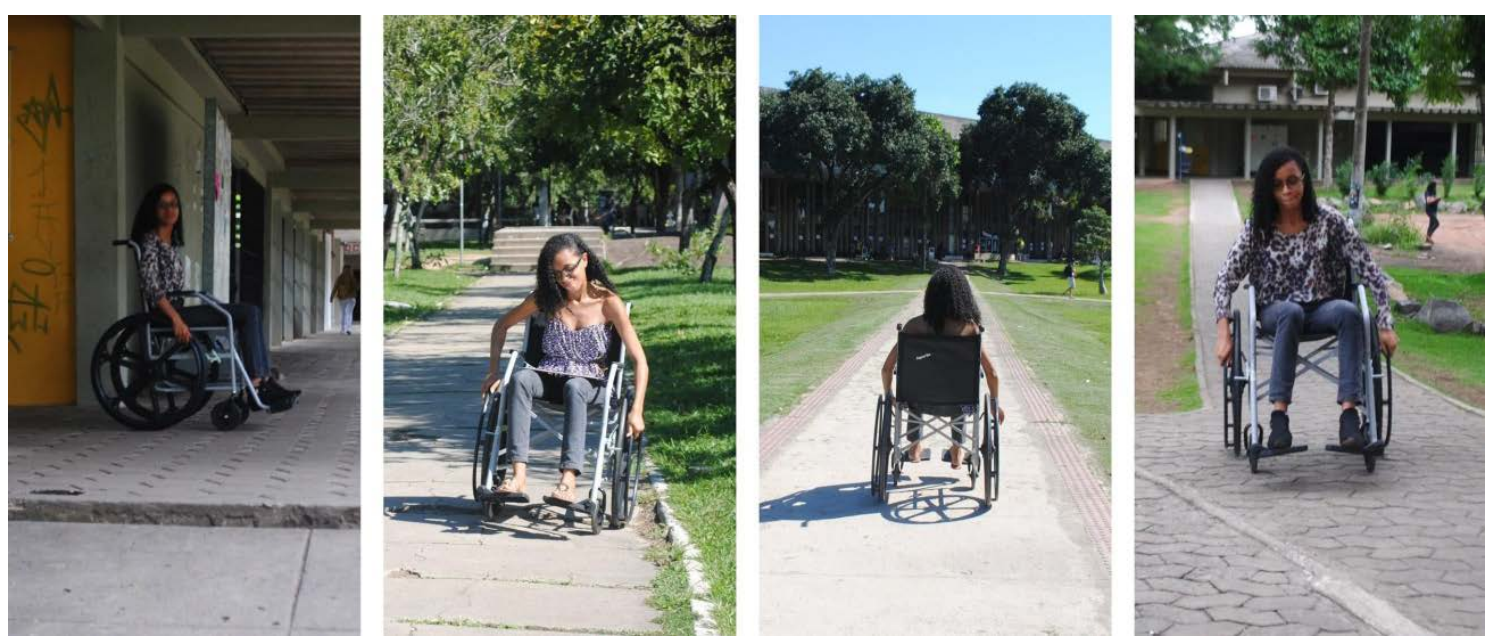

Figura 4: pesquisadora analisa os caminhos do campus com a cadeira de rodas.

Fonte: elaborado pelos autores, com base na pesquisa realizada

\subsection{Organizando as etapas de análise}

Dada a grande quantidade de caminhos existentes no campus, foi preciso estabelecer uma lógica que ajudasse a ordenar a sequência de caminhos a serem avaliados. Para tanto, baseamo-nos no sistema descrito por Gomes, Pinheiro e Carnielli (2015). Os trajetos de verificação com a cadeira de rodas se iniciavam nos pontos de ônibus localizados em frente à Ufes, e tinham continuidade nos eixos principais localizados já dentro da universidade, pelos quais ocorrem os maiores fluxos de pessoas - conforme identificado no estudo realizado por Pinheiro, Gomes e Rocha (2015). Através desse procedimento foram analisados os principais caminhos utilizados por quem é portador de deficiência física.

Durante a verificação com a cadeira de rodas, a equipe realizava registros fotográficos dos trechos percorridos, destacando os problemas encontrados no caminho. Em paralelo a isso era a feita a marcação no mapa da Ufes com a cor correspondente à qualidade do caminho. Cada cor significava o grau de severidade percebido, de acordo com a seguinte escala:

- Impossível (vermelho) - caminho esburacado, obstáculos graves, rampas muito inclinadas;

- Ruim (laranja) - rampas levemente inclinadas, obstáculos leves, material do calçamento inadequado;

- Regular (amarelo) - leves desníveis;

- Bom (azul) - caminho acessível;

Após percorrer os eixos principais por completo, foi feita a verificação dos trechos de ramificações, que davam acesso aos prédios. Estes trajetos também foram fotografados e a situação encontrada foi indicada no mapa (Figura 5). 


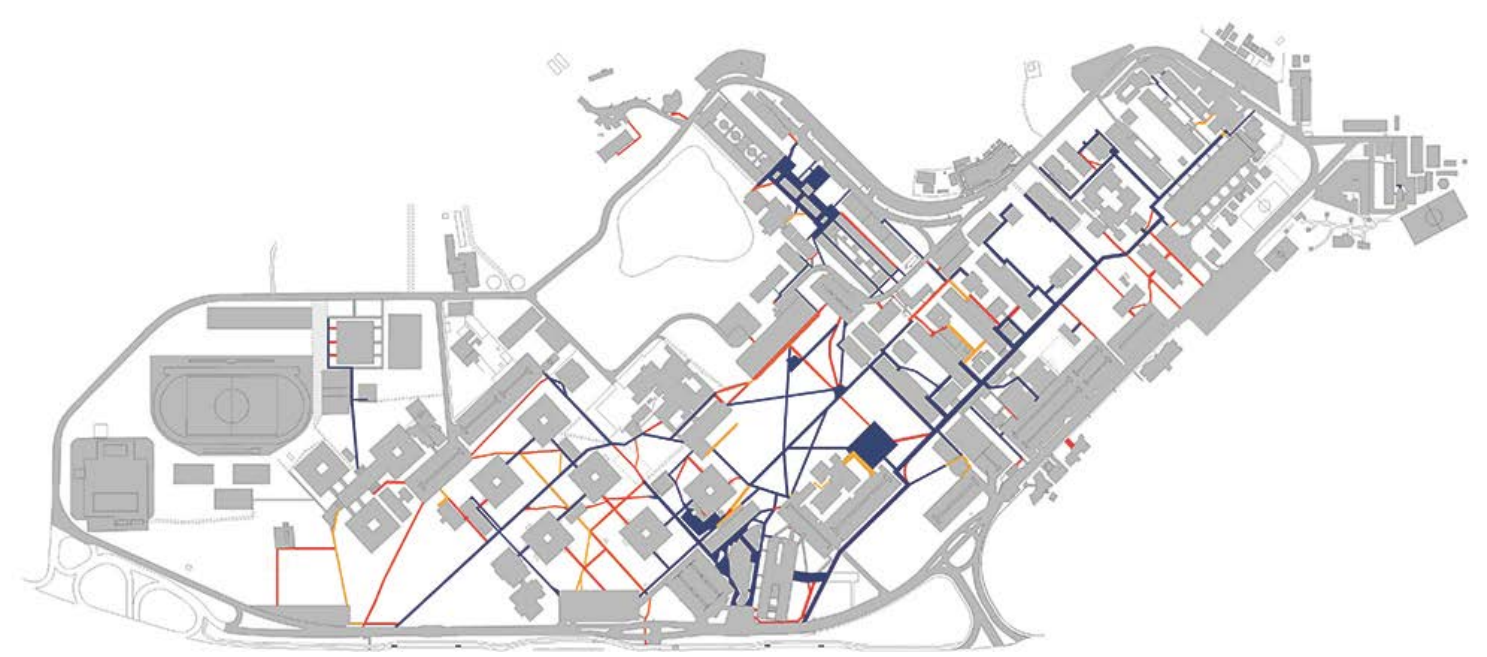

Figura 5: resultado final e todo o levantamento realizado.

Fonte: elaborado pelos autores, com base na pesquisa realizada

Além dessas etapas, foram realizadas entrevistas com estudantes e servidores da Universidade que são cadeirantes, buscando ter uma visão aproximada dos problemas enfrentados diariamente em seus percursos pela Ufes, tais como: quais os pontos que necessitavam de uma reforma urgente, quais locais apresentavam um caminho adequado para servir de referência, quais projetos a universidade disponibiliza visando a inclusão. Com esses dados em mãos, concluiu-se a etapa de análise da situação de acessibilidade dentro do campus.

\subsection{Comunicando os problemas percebidos}

Para facilitar o entendimento por parte dos gestores e demais envolvidos com as questões de acessibilidade no campus, foi necessário compilar e apresentar os resultados da pesquisa de maneira simples e direta. Embora o mapa representasse a situação de modo mais geral indicando os diferentes graus de dificuldade dos caminhos percorridos, o detalhamento dos problemas ainda dependia do conhecimento da equipe do laboratório. Um documento em formato de relatório corria o risco de deixar a leitura pouco atraente para os gestores - sempre envolvidos em diversas atividades.

Foi elaborado um manual, organizando os trajetos por regiões do campus (em consonância com o projeto de sinalização realizado pelo ProDesign Ufes) e destacando os problemas específicos percebidos em cada trecho (Figura 6). Esse manual é uma evolução da documentação desenvolvida anteriormente quando foi feita a análise dos estacionamentos. Como o manual seria usado pela Prefeitura Universitária para planejar as ações mitigantes, nesta versão optou-se por criar documentos distintos de acordo com o nível de complexidade de resolução dos problemas. 


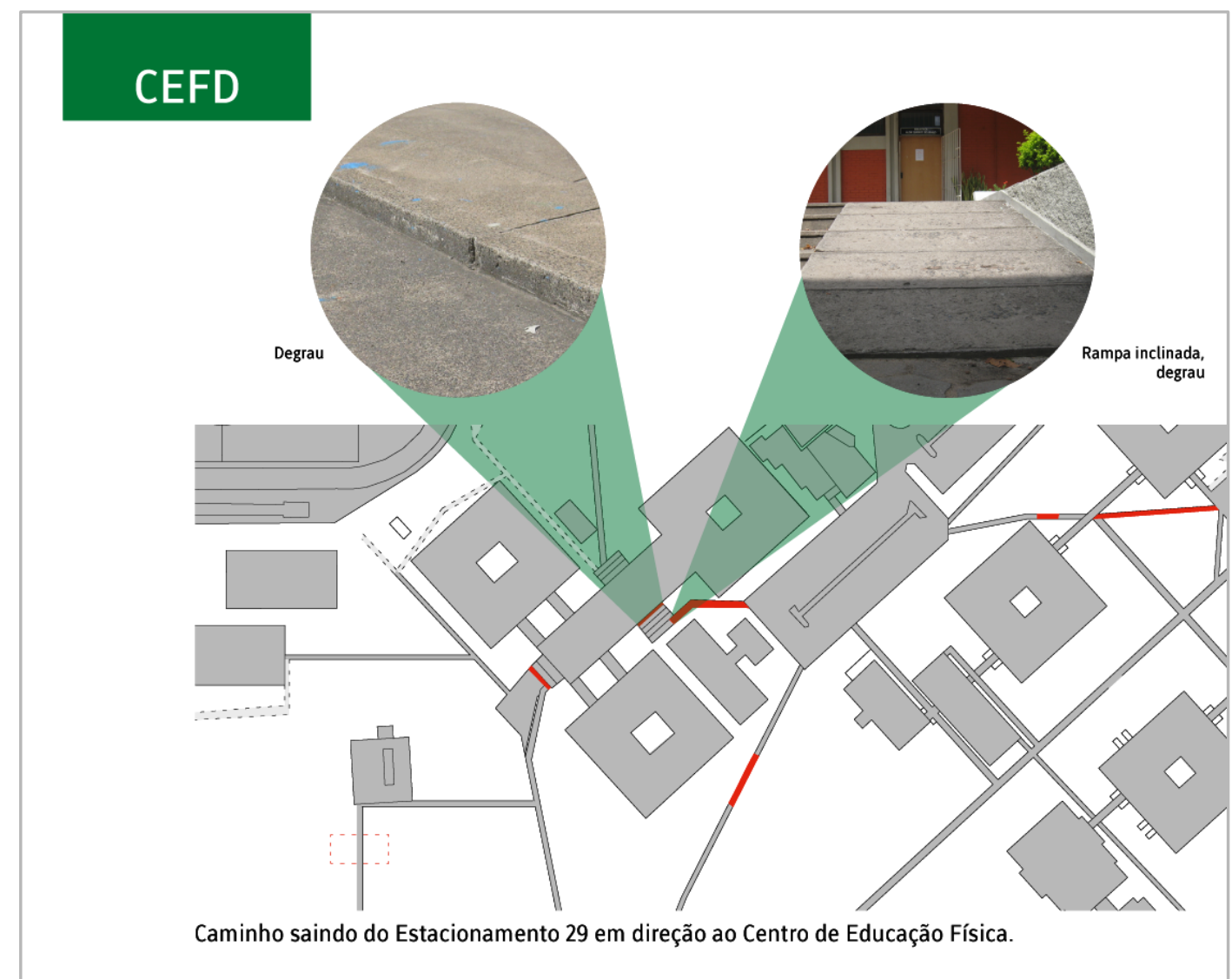

Figura 6: página do manual, destacando os trechos que apresentaram problemas. Para cada problema encontrado, destaca-se a foto do problema no local e sua respectiva descrição.

Fonte: elaborado pelos autores, com base na pesquisa realizada

Além do manual, foram feitas novas versões de mapas de acessibilidade (Figura 7), destacando os pontos críticos em forma de ícones (Figura 8), de acordo com a natureza do problema percebido. Assim como no manual, os diferentes mapas deveriam agrupar problemas de mesma complexidade - um mapa somente com problemas de baixa complexidade, outro para média complexidade etc. 


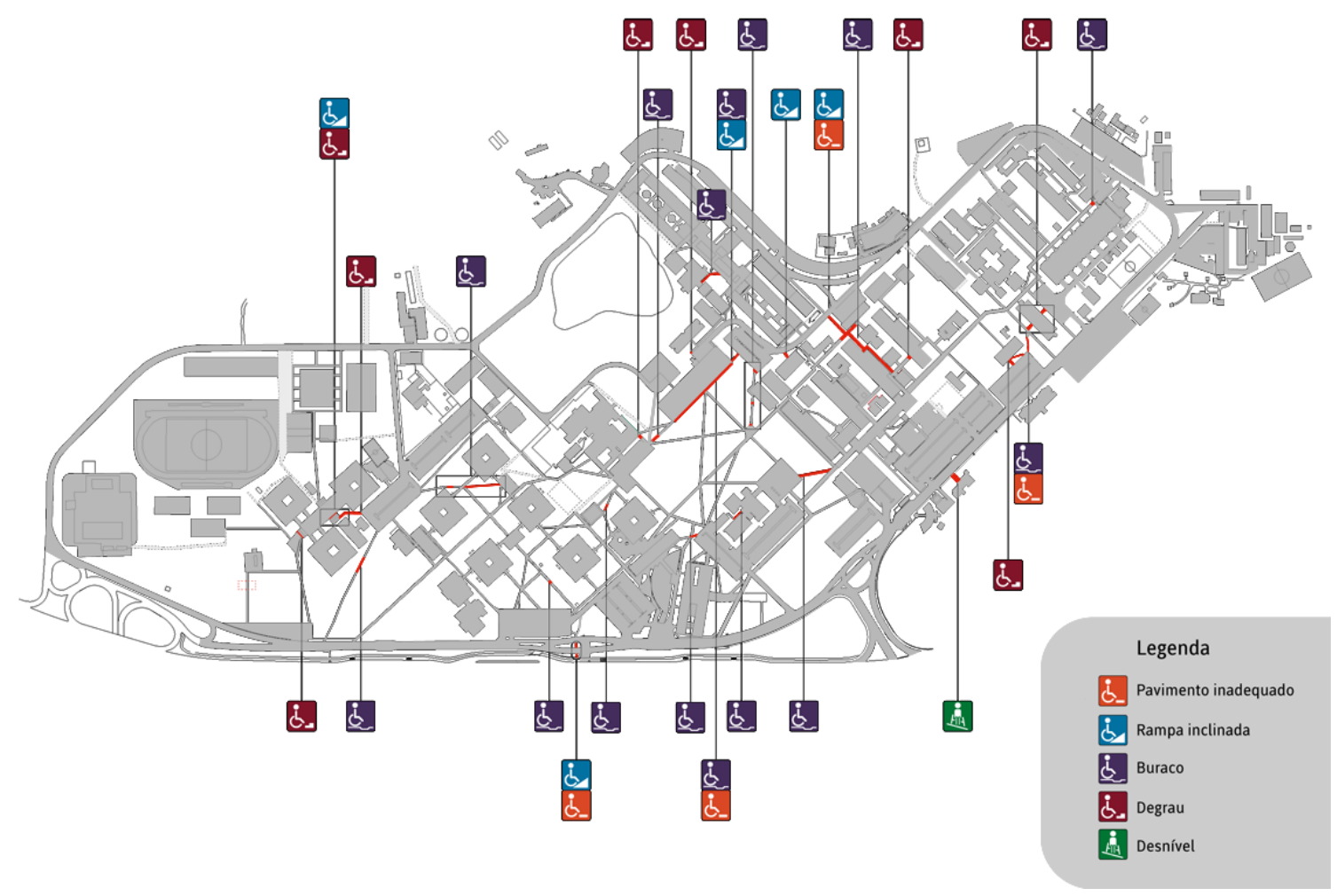

Figura 7: mapa com os problemas de baixa complexidade representados Fonte: elaborado pelos autores, com base na pesquisa realizada

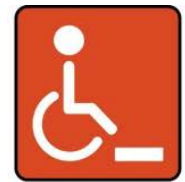

Pavimento inadequado

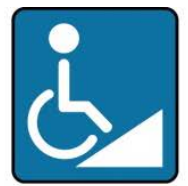

Rampa inclinada

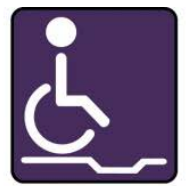

Buraco

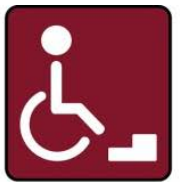

Degrau

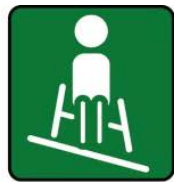

Desnível

Figura 8: família de ícones desenvolvida

Fonte: elaborado pelos autores, com base na pesquisa realizada

\section{REPERCUSSÃO DO TRABALHO}

Como já mencionado, o mapeamento de acessibilidade da Ufes teve início como um desdobramento do projeto de sinalização realizado nos campi da universidade. Como a pesquisa foi uma iniciativa da equipe do ProDesign Ufes, portanto inesperada, desde a primeira apresentação para a Reitoria - ainda apenas com o mapeamento da situação dos estacionamentos - foi possível perceber o impacto causado pela análise realizada. O formato de apresentação dos dados sem dúvida contribuiu para tanto, facilitando o entendimento dos problemas vivenciados. Além disso, cumpre lembrar que - Governo Federal vêm incentivando (e cobrando) ações de acessibilidade nas universidades federais, o que potencializa o interesse pelo tema.

A partir desse trabalho, o ProDesign Ufes foi convidado a participar do Comitê de Acessibilidade da Ufes, que congrega diversos setores da universidade envolvidos de alguma forma com questões de acessibilidade, a saber: o Núcleo de Acessibilidade da Ufes; a Pró-Reitoria de Graduação; a Pró-Reitoria de Extensão; a Pró-Reitoria de Assuntos Estudantis e Cidadania; a Prefeitura Universitária; a Pró-Reitoria de 
Planejamento e Desenvolvimento Institucional; a Pró-Reitoria de Gestão de Pessoas. O objetivo desse comitê é unificar as ideias e propostas, e desenvolver projetos visando melhorar a acessibilidade da universidade. A análise dos caminhos da Ufes realizada pelo ProDesign Ufes foi apresentada ao comitê, que decidiu priorizar os problemas identificados como de fácil resolução.

Algumas ações já vêm sendo tomadas. Destaca-se a construção de rampas de acesso nas entradas da Universidade, que apresentavam desníveis entre a rua e a calçada (Figura 9). Após a identificação desse ponto pela pesquisa, foram construídas rampas nas principais entradas da universidade - mesmo nas calçadas das vias públicas, cuja responsabilidade é do governo municipal.
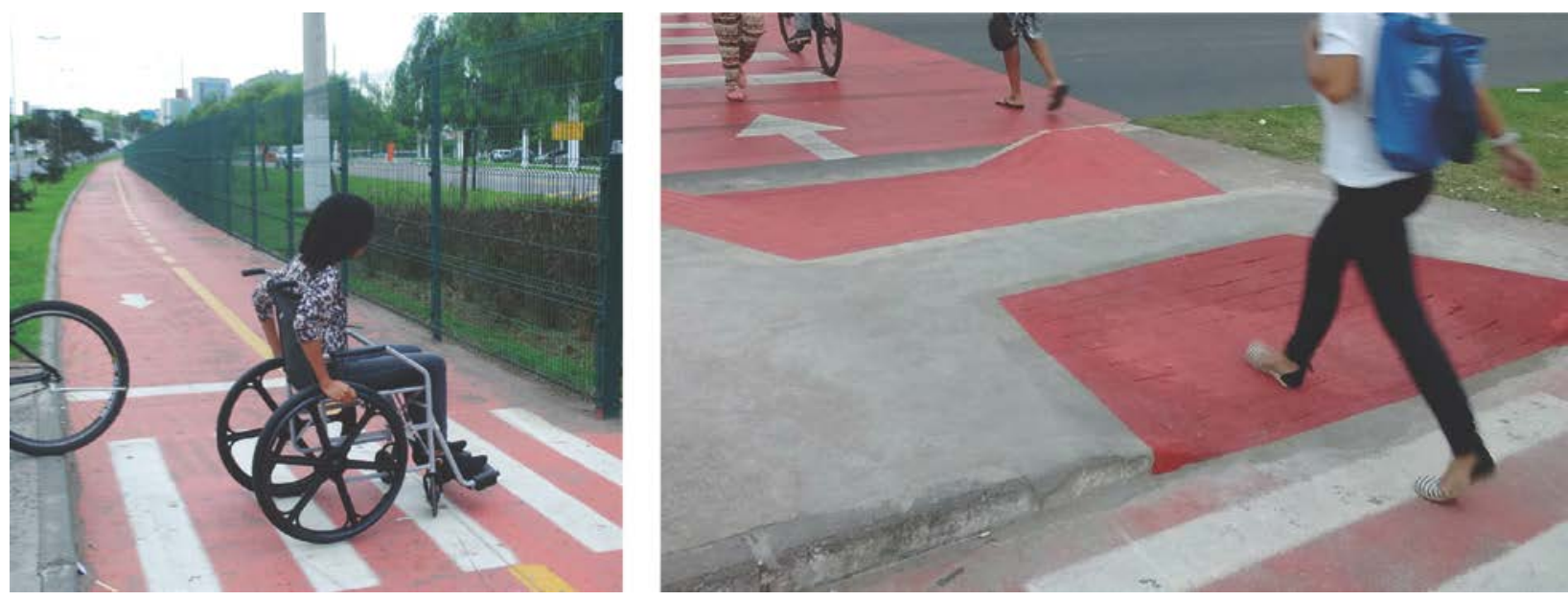

Figura 9: à esquerda, a passagem antes da construção da rampa, com desníveis entre a rua, a calçada e a entrada da Ufes. À direita, a rampa construída após a identificação do problema na pesquisa.

Fonte: elaborado pelos autores, com base na pesquisa realizada

\section{CONSIDERAÇÕES FINAIS}

O tema da acessibilidade é extremamente importante. Como os próprios cadeirantes costumam ressaltar, não se trata simplesmente de tornar os caminhos - e construções, espaços etc. - acessíveis a eles, mas a todos. Em tese, se for acessível a um cadeirante, será acessível para pessoas idosas, para pessoas com mobilidade reduzida e diversos tipos de deficiências físicas. Trata-se portanto de uma preocupação efetivamente com o Design Universal. Infelizmente, ainda hoje esse tema parece não ter a penetração que merece, haja visto que mesmo na Universidade Federal do Espírito Santo ainda se observa novas construções e sistemas que pecam em questões básicas de acessibilidade.

O ProDesign Ufes trabalha no sentido de desenvolver projetos inclusivos, que respeitem as diferenças e promovam a melhoria da qualidade de vida das pessoas, tenham elas deficiências físicas ou não. O mapeamento de acessibilidade do campus Goiabeiras foi mais um passo nesse sentido, buscando minimizar os problemas percebidos durante o desenvolvimento do projeto de sinalização. Outras iniciativas de natureza semelhante estão em andamento, e o tema da acessibilidade já é uma constante em nosso laboratório.

Esperamos que o trabalho aqui apresentado sirva de inspiração para que mais e mais pessoas tratem do tema da acessibilidade. O Design, como campo de conhecimento que atua na concepção de interfaces que potencializam a ação do 
homem no mundo, tem um papel fundamental na melhoria da qualidade de vida das pessoas e na criação de um mundo mais democrático, onde todos tenham as mesmas condições de participação como cidadãos.

\section{REFERÊNCIAS}

ABNT - Associação Brasileira de Normas Técnicas. NBR 9050:2015 - Acessibilidade a edificações, mobiliário, espaços e equipamentos urbanos. 3aㅡ. Ed. Rio de Janeiro: ABNT, 2015

BONSIEPE, Gui. Design: do material ao digital. Florianópolis: FIESC/IEL, 1997.

BRASIL. Constituição da República Federativa do Brasil de 1998. Disponível em: <http://bit.ly/constituicao1988>. Acesso em: 12 maio 2016.

BRASIL. Lei no 13.146 de 6 de julho de 2015. Disponível em: <http://bit.ly/lei-131462015>. Acesso em: 12 maio 2016.

BRASIL. Decreto Legislativo no 186, de 9 de julho 2008. Disponível em: <http://bit.ly/decreto-186-2008>. Acesso em: 12 maio 2016.

BRASIL. Lei no 10.098 de 19 de dezembro de 2000. Disponível em: <http://bit.ly/lei10098-2000>. Acesso em: 12 maio 2016.

GOMES, Ricardo Esteves ; PINHEIRO, Mauro ; CARNIELLI, Viviani . Maquetes e mapas de fluxo: ferramentas para o design da sinalização do Centro Universitário Norte do Espírito Santo (Ceunes-XXXX). In: Anais 70 Congresso Internacional de Design da Informação, 2015, Brasília. 7th Information Design International Conference Proceedings, 2015.

PINHEIRO, Mauro, GOMES, Ricardo E. \& RAMOS, Matheus. R. S. Desenhe seu trajeto. Revista Brasileira de Design da Informação, Rio de Janeiro, v. 12, n. 2, p. 194 - 208, out. 2015. Disponível em: <http://www.infodesign.org.br/infodesign/article/view/394/231> OLIVEIRA, Luiza Maria Borges. Cartilha do Censo 2010 - Pessoas com Deficiência. Brasília: Secretaria de Direitos Humanos da Presidência da República (SDH/PR) / Secretaria Nacional de Promoção dos Direitos da Pessoa com Deficiência (SNPD), 2012. Disponível em: $<$ http://www.sdh.gov.br/assuntos/pessoa-com-deficiencia/dados-estatisticos/pesquisasdemograficas $>$. Acesso em: 12 maio 2016. 